\title{
Chapter 2 \\ International Migrations \\ and the Management of Identity \\ by the State
}

\section{Introduction}

Despite meeting opposition, intercultural approaches to education have still been able to spread. International migrations form a typical part of global phenomena and have resulted in the adoption and legalization of these approaches in many countries. In this chapter, we will look initially at the extent and evolution of international migrations in the world. Then, we will address the different models of access to citizenship. Finally, we will analyse the consequences of restricted access to citizenship for children and young people from migratory backgrounds.

\section{International Migrations: An Everlasting Phenomenon}

Changing one's place of residence is a reflex as old as human history. Indeed, nomadism in the search for a better way of life was the early reality for human populations as soon as they left humanity's African cradle. More recently, tens of millions of people left Europe between the middle of the nineteenth century and the beginning of the Second World War emigrating in search of a more prosperous life. Thus, between 1815 and 191560 million Europeans emigrated to the Americas in order to flee economic hardship and poverty (Chaliand, Jan \& Rageau, 1994).

Until the beginning of the twentieth century, there was very little administrative supervision of these migrations. It was between the wars that they fell increasingly under State control, mainly for reasons of national security or the preference of host countries to select people from particular origins.

Following the Second World War, migrations began again due to the shortage of manpower in Northern Europe and North America. Industrialized European countries satisfied their needs for manpower from European regions that had experienced less industrialization (Southern Europe), but also from their former colonial empires. France looked mainly towards North Africa; the United Kingdom towards 
the West Indies and the Indian sub-continent. For a long time, the host societies only recognized the migrants as workers, since any other aspect of their existence was considered secondary and irrelevant (Sayad, 2006). However, we note that the definition of these migrants as "invited workers" or "immigrant workers" might have contributed to the legalization of their presence within the host countries. Today, vague terms are employed, such as "migrants" and "refugees", or these first- or second-generation migrant populations are identified by their religion (for example, French Muslims). This quick glance at questions of people's denomination following migration is necessary. In fact, these terminological issues are important in the eyes of the ideological assumptions they are supposed to inform. For example, in France, Gastaut (1997) detected a modification of the term "foreigner" to "migrant" which, in the 1960s, referred more to the origin or the cultural affiliation than to their true migratory status. The author also explains that the use of the term "migrant", applied to (second- and third-generation) children from migrant families, has strengthened its negative connotation. More recently, the discussion has once again focused on the term "migrant", but this time as the antithesis to the term "refugee". Calabrese (2018) describes the numerous tensions raised by the media concerning the social realities that these terms define. From the viewpoint of these sources, it would seem that people's denomination contributes to the recognition of their way of life and the place that society wishes to grant them. Reflection about the Other arising from intercultural approaches should then encourage a process of reflection about the words describing the world.

Since the 1970s and the first oil crisis, the supervision of international migrations has become stricter, particularly within the European Union and other industrialized countries. After several successive attempts at regulating migrations, controls have become more severe. It is for this reason that migratory movements underwent a deceleration during the 1990s, even if they did not stop altogether. European countries that have been long-term exporters of migrant workers, such as Italy and Spain, gradually became host countries for a new wave of migrants. Nowadays, international migrants represent a significant part of the total population in some countries, such as Australia, Canada, Switzerland and the United States of America.

Migrations from and to the countries of the Global South began to expand from the 1970s onwards, encouraged by two principal factors: on the one hand, the wealth of the oil exporting countries; and on the other, the development of emerging economies. For example, the Arabian Gulf countries accepted millions of migrant workers coming for the most part from Asia. In Africa, countries such as South Africa and Ivory Coast have welcomed millions of migrants from all over the continent, drawn by the mining industry and the boom in cocoa.

Encouraged by both advances in transportation but also by interdependence and economic globalization, contemporary international migrations take place on a global scale. Today, the International Organization for Migration (IOM) believes that 244 million persons, or $3.3 \%$ of the world's population, can be considered as international migrants (as of 2015, McAuliffe et al., 2017). ${ }^{1}$ It should also be noted that different

\footnotetext{
${ }^{1}$ Publishers of the World report on migration 2018 for the International Organization for Migration.
} 
conflicts affecting several of the world's regions have contributed to an increase in migrations (as of 2016, IOM counted 22.5 million of such persons as refugees across the world), ${ }^{2}$ mainly in countries bordering on conflict zones, but also in wealthy countries.

If $3.3 \%$ of the world's population currently live in a country other than their place of birth, it is both a little and a lot. Little in terms of overall demographics. A lot if we consider the degree of concentration of this population in the urban and prosperous regions of the globe.

Among them, some people find themselves in "irregular situations", which means that they are not authorized to stay in the host country. According to OIM, it is difficult to give a precise figure on this group of migrant people in view of the elasticity of the concept of irregularity (there are many ways of ending up in an irregular situation varying from one's place of birth to the expiry of a work permit), but also because of different national laws governing migrations (McAuliffe et al., 2017).

These initial descriptions of migratory situations should lead the reader to conclude that they are complex. One must constantly keep in mind that migrations are accelerating in several directions (mainly North-North, South-South, North-South) and that "nearly all countries in the world are concerned by the departure, the arrival and the passage of people" (Wihtol de Wenden, 2009, p. 75).

Furthermore, the figures concerning migrations are liable to be interpreted in different ways. When comparing the number of migrant people to the world's population, the total number might appear slight. Indeed, the vast majority of people living in the world today will not leave the country of their birth. Nevertheless, if we were to take into consideration all the potential numbers of people who are seeking to change countries to escape difficult living conditions, these figures might then seem more important. Added to which, the concentrated domiciliation of migrant populations within the host countries might sometimes give the impression that they represent a considerable part of the global population. Finally, in examining these figures, one should avoid an overestimation influenced by a fear of migrant people and exaggerated accounts about them.

Even if population movements grow on a global scale, few countries in the world would label themselves and officially declare themselves as countries of immigration. Population movements often reflect social and economic breakdowns, ecological problems and growing economic inequalities between the poorest and the richest countries on the planet.

From a strictly demographic and economic point of view, South-North international migrations are indispensable for a number of rich countries in order to overcome their demographic decline, to maintain their economic prosperity and their present standard of living (Frenkel, 2017). Nevertheless, the flow of migrants

\footnotetext{
2 In 2016, coming mainly from Burundi, the Central African Republic, the Democratic Republic of the Congo, Eritrea, Myanmar, Somalia, Southern Sudan, Sudan and Syria (McAuliffe et al., 2017).
} 
Table 1 The number and annual growth rate of migrants in the world by region

\begin{tabular}{l|r|r|r|r|r}
\hline \multirow{2}{*}{} & \multicolumn{3}{|l|}{ Number of migrants (millions) } & $\begin{array}{l}\text { Average annual } \\
\text { growth rate }\end{array}$ \\
\cline { 2 - 6 } & 1990 & 2000 & 2010 & 2017 & $2000-2017$ \\
\hline World & 152.5 & 172.6 & 220.0 & 257.7 & 2.4 \\
\hline Africa & 15.7 & 14.8 & 17.0 & 24.7 & 3.0 \\
\hline Asia & 48.1 & 49.2 & 65.9 & 79.6 & 2.8 \\
\hline Europe & 49.2 & 56.3 & 70.7 & 77.9 & 1.9 \\
\hline Latin America and the & 7.2 & 6.6 & 8.2 & 9.5 & 2.2 \\
Caribbean & & & & & \\
\hline North America & 27.6 & 40.4 & 51.0 & 57.7 & 2.1 \\
\hline Oceania & 4.7 & 5.4 & 7.1 & 8.4 & 2.7 \\
\hline
\end{tabular}

Source United Nations (2017)

to host countries encounters, both in the countries of the North and the South, opposition provoked by popular demagogues and by the rise to power of the extreme right in some European countries and in the United States, inspired by the fear of international terrorism.

\section{The Present Distribution of International Migratory Flows and Their Impact on Education Systems}

The number of migrants in the world today is estimated to be a little less than 250 million. Immigrants, defined as people resident in a country other than that of their birth, represent 3.3\% of the global population (McAuliffe et al., 2017). Analysing migratory flows and trends, the United Nations Organization emphasizes that immigration contributed $42 \%$ to population growth in North America between 2000 and 2015. Without a similar contribution, the population of Europe would have declined during this same period. The United States, with almost 50 million individuals, is the host country with the most migrants, while Saudi Arabia, Germany and Russia each number about 12 million (United Nations, 2017).

Table 1 sums up the flow of migrants today by world region. According to this source, ${ }^{3}$ between 1990 and 2017, the number of migrants has increased from 152.5 million to 257.7 million, with an annual average growth rate of $2.4 \%$.

An examination of the international flow of migrants allows a certain number of preconceived ideas to be overturned. The increase in the number of migrants in developed regions is the outcome of the growth in the number of migrants coming

\footnotetext{
${ }^{3}$ As mentioned earlier, it is sometimes difficult to estimate the number of people who have left their country. Furthermore, we believe that the categorization of migrant persons can bring about slight changes during censuses of migrant persons.
} 
from both the South and the North. Of the 65 million international migrants reaching the North between 1990 and 2017, 48 million, or 76\%, were born in the South. The remaining 16 million, that is $24 \%$, came from Northern countries. In Switzerland and Germany, a large number of migrants came from neighbouring European countries (France, Italy, Spain). In the countries of the South, the increase in the migrant population resulted mainly from people who had been born in the South. Between 1990 and 2017, the migrant population originating in the South and living in the South grew from 57 to 97 million, an increase of $70 \%$. Of the 41 million people born abroad and who migrated in the South during this period, about $96 \%$ were born in developing regions, while only $4 \%$ originated in countries of the North (United Nations, 2017). It is therefore necessary to examine migration in all of its complexity and in the context of the growing globalization of migratory flows. Moreover, some countries, where restrictive migratory policies have come into force, count among the twenty countries in the world with the most migrants. As an illustration, we may mention Italy or the United States (for the year 2015, McAuliffe et al., 2017).

On a global scale, in 2017 14\% of all migrants were less than 20 years old. The proportion of young migrants was considerably higher in developing regions $(21 \%)$ than in developed regions (less than 9\%) (United Nations, 2017). In a report dating from 2014, the Global Migration Group (GMG) drew attention to several reasons to explain why very young people migrate: study abroad, the search for employment, family reunifications and the quest for protection (concerning requests for political asylum, for example). These are the main reasons for them wanting to go abroad. Nevertheless, the report states that these reasons are largely conjecture, because data about young people are relatively rare (GMG, 2014).

Europe has been the destination of a net flow of migrants for several decades. However, with the economic crisis of recent years and the growth in power of xenophobic movements, more restrictive migratory policies have entered into force in numerous countries, and several countries have even envisaged a situation of zero migration.

While this topic mainly concerns humanist ideals, solidarity among peoples and the preservation of each person's right to dignity, a few economic arguments are sometimes put forward to convince the most unwilling of migration's beneficial effects. Beyond a cultural mingling which is a source of enrichment, some authors have drawn attention to aspects connected with productivity issues and a country's rates of innovation. Livi Bacci (2018) highlights, for example, the need for Europe to attract significant streams of migrants if it wishes to maintain a reasonable level of economic growth.

Moreover, between 2015 and 2050, and without any migration, the European population would decline in most countries, including the active population, even if there were an increase in the national active population's productivity and the retirement age was raised.

Whether the rich countries decide on a policy of restriction or openness to immigration, their education systems will be faced with the management of cultural diversity for a long period to come. Indeed, the number of children in the education system who were born abroad has today reached unprecedented levels (Fig. 1). 


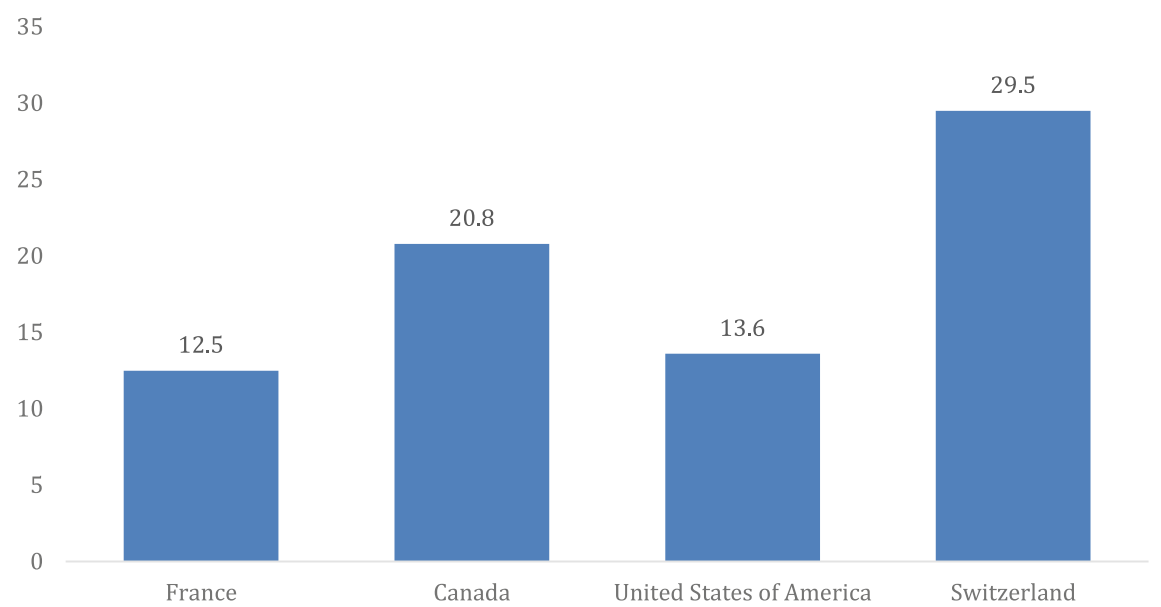

Fig. 1 The proportion of the population born abroad in 2018 (as a percentage) ${ }^{4}$ Source OECD (2020). https://doi.org/10.1787/7f230fe7-fr

\footnotetext{
${ }^{4}$ These statistics include people born abroad, holding the citizenship of the country they are living in (OECD, 2020).
}

Furthermore, the descendants of migrants will be increasingly numerous in educational institutions. It will be seen that, for both primary and secondary education in many countries in the North, the enrolment of migrant and refugee children will avoid the closure of classes resulting from the ageing of the population. There will even be occasions when new classes have to be opened to deal with the flow of new arrivals. This will have a beneficial effect not only on the renewal and maintenance of educational infrastructures, but also on the employment of teachers.

The development of intercultural approaches in education is closely linked to our understanding of migratory flows. The diversification of pupils' ways of life, origins and mother-tongues has obliged the school to develop different strategies to adapt to a new, increasingly diverse school population. The national experiences described in this book show that educational policies have been set the task of facilitating the arrival and integration of migrant pupils on four levels within the existing education system:

1. Creating appropriate institutions and structures responsible for assisting the arrival, the learning of teaching languages and the necessary links with the mother-tongues.

2. The reform of pre-service and in-service teacher training to satisfy migratory issues and cultural diversity. 
3. The development of intensive psychosocial support, particularly for children arriving from conflict zones.

4. The integration of the migrants' cultural and linguistic heritage into educational policies and programmes.

Through the theoretical chapters and the case studies, we will discover in this book the different ways in which States have assumed responsibility for the pupils' cultural diversity by analysing the four levels mentioned above.

\section{Access to Citizenship and Multiple Affiliations}

Faced with migrant populations from diverse origins, national policy-makers have come up with a variety of responses (Windisch, 2000). To begin with, a distinction must be drawn between the countries which would declare themselves to be long-term migrant countries, such as Australia, Canada or the United States, and those countries that have sought a short-term remedy resorting to foreign workers to fulfil the important needs of their economies (for example, France, Germany, Italy, Spain and Switzerland), even if they ultimately became countries whose populations contained a large number of foreigners. While these two categories are often confused with each other, it should be noted that, over recent decades, the second category has found itself faced with the long-term residence of numerous communities originating abroad and is now involved in an intense debate about national identity.

One way of analysing the way in which countries see themselves with regard to international migrations is to examine their procedures for granting access to their nationality. Indeed, obtaining it is an important factor in coming to grips with cultural diversity, to the extent that it includes the possibility — or not—of equality before the law for all of a country's inhabitants.

The matter of nationality and its linkage to citizenship has initiated several discussions. On this subject, Andrès (2013) identified two basic attitudes which must be elucidated to understand the issues underlying the process of naturalization. Firstly, he designates a position in which nationality is a synonym for citizenship. It is a condition for belonging to the nation and thus proving one's loyalty (Andrès, 2013). In this case, the citizen's political commitment (the vote) requires the foreigner to "express allegiance to his/her new State through a naturalization procedure" (Andrès, 2013, p. 104). Secondly, this author establishes another position in which citizenship and nationality are two separate issues. Thus, the participation in local political life (for example, the right to vote) demonstrates the individual's citizenship, while his/her nationality refers only to an "ethnocultural or identity" affiliation (Andrès, 2013, p. 104).

The matter of being awarded a nationality has also been discussed from an international legal point of view, since every individual has the right to a nationality, while access to it is governed by a sovereign State (Carlier, 2003). If statelessness (having no nationality) is to be avoided at all costs, this does not necessarily mean 
that States "must" grant their nationality to each individual (Carlier, 2003). On this subject, Carlier (2003) establishes a tension between human rights and nationality, since the latter confers rights that could make individuals unequal. He clarifies that, since it includes people into a national space, it excludes others from it.

To these concepts, the notions of race and ethnocultural community in some States can be added, which are employed in official documents and in laws. Côté (2012) defines the notion of the ethnocultural community as:

a process of identity construction (ethnicity) on the basis of a shared culture. The level of belonging and the type of cultural referent which is employed in this process may vary from one group to another and from one individual to another within the same group. Cultural references are multiple: language, geographic region of origins, religious and spiritual practices, trades, family or social class. Besides, identification with an ethnocultural community is an expression of a voluntary social distancing or not from the dominant cultural model of the society in which one lives and the historical values that it represents (p. 2-3).

In modern laws on nationality, two systems are used with multiple shades or combinations of meaning: birth-right citizenship (jus soli) or the right of blood (jus sanguinis). The birth-right principle awards nationality to any child of foreign parents born on the national territory. The acquisition of nationality is not, however, automatic. France bases the acquisition of French nationality on the birth-right principle according to the situation. Here is an example. ${ }^{5}$

A child is French if born in France when at least one of its parents is born there himself/herself. Simply being born in France does not justify the award of French nationality unless the child is born of unknown or stateless parents, or of foreign parents who have not transmitted their nationality (France Diplomatie, 2018).

This system of birth right is valid in countries such as in Canada, France, the United Kingdom and the United States.

The right of blood, valid in all countries, grants the parents' nationality to the child, independent of where it was born. This system gives absolute priority to family connections, and any person who does not descend from native ancestors is considered as a foreigner.

This system dominates in cultures strongly steeped in tribal or clan traditions, but also in countries of Germanic culture such as Germany, Austria and Switzerland. These last two countries are also among the European countries that require the longest number of years of residence in the country before being able to submit a request for naturalization.

It is difficult to accept the right-of-blood system in a situation experiencing strong international migration since it runs the risk of transforming a large number of inhabitants into "second-class" citizens due the impossibility of exercising their political rights. It is for this reason that the birth-right system has recently gained ground

\footnotetext{
${ }^{5}$ Certain other situations are described in the text of the law, but we will not dwell on them here. The reader can find more information at: https://www.immigration.interieur.gouv.fr/Accueil-et-acc ompagnement/La-nationalite-francaise/Les-conditions-et-modalites-de-l-acquisition-de-la-nation alite-francaise.
} 
on the right-of-blood system. For certain members of the majority group, the birthright system might appear to be too indulgent, even a threat to national identity. It seems that those countries with a law of nationality based on birth right, granting a host country's nationality practically automatically to all second-generation young people, are more successful in integrating their immigrants. On this matter, it would appear useful to compare France and Germany, which apply respectively the birthright and the right-of-blood system. For example, the rate of female exogamy in France (exemplified by the number of children born to an Algerian mother and a native French father) evolved from $6.2 \%$ to $27.5 \%$ between 1975 and 1990 . Over this same period, the rate of female exogamy in Germany (exemplified by the number of children born to a Turkish mother and a native German father) evolved from $0.5 \%$ to $1.2 \%$ (Clément \& Girardin, 1997).

We can see from these figures that mixed marriages are far more frequent in France than in Germany. The system providing access to nationality explains this difference to a certain extent, even if other explanations could also be put forward. It should, however, be noted that access to nationality in Germany has become far more flexible since the beginning of the present century. Nationality is granted to children of foreign parents if they have been resident in the country for several years or if they hold a residency permit. In France as well, there have been a few failed tentative political initiatives to modify the law such that it would no longer automatically grant French nationality to children born in the country to foreign parents. The right wing and the far right have never abandoned this campaign. We can also observe that each country has its own way of managing the possibility of possessing two nationalities (forbidden, tolerated or accepted).

Fougère and Safi (2005) explain that naturalization is often "perceived as the 'ultimate' step in integration. For this reason, it is often regarded from the point of view of the individual rather than that of the host society. It is considered as successful assimilation" (p. 169). Nevertheless, as we shall discover in the following chapter, different processes of acculturation, particularly integration, do not depend solely on the individual's foreign origin; it is necessary to consider the attitude of host societies regarding foreigners or people with migratory backgrounds.

Indeed, we understand that people, despite their legal national affiliation, are not always viewed in the same way. On this subject, to describe someone as a native is a controversial demographic or statistical definition, used particularly in a certain number of demographic studies in France and Quebec. They apply to autochthonous people (that is to say, natives, without any foreign heritage). In modern parlance, certain expressions indicate the difference between native people and the others. In Quebec, for example, the expression québécois pure laine is used compared to the québécois sur le papier. In Malaysia, the term Bumiputra ("son of the earth" in Malay) is used for native inhabitants of the country, as opposed to migrants who are probably Malaysians of Chinese or Indian extraction. The idea of native is frequently encountered in public discussions. It can lead to the establishment of a hierarchy between individuals and lead to inequality before the law (for the purchase of property and entry to certain professions). 
More recently, the wave of refugees arriving in Europe across the Mediterranean has revealed the devastating consequences of armed conflicts and economic and humanitarian crises on populations. A certain number of countries have distinguished themselves by their generosity in welcoming refugees. This is the case of Germany which, even faced with the political rise of the extreme right, welcomed more than a million Syrian refugees and introduced ambitious measures to facilitate their effective integration into German society through schooling, training and access to employment (Kersting, 2018).

\section{The Generations Arising from Migration in Society and the School}

A consequence of the development of international migrations was the classification of different generations of migrants (first, second, third generation). The difficulties of acquiring citizenship in countries following principally the right of blood led to some young people being assigned an identity. They were entitled to the nationality of their parents even though they had not learned to speak the official language of their country of origin. Likewise, even though they had lived their entire lives in the host country, their restricted access to its nationality could stigmatize them and prevent them from participating fully in local political life. This restriction also implied their permanent status as foreigners; their status "outside" the nation with which they could or would identify themselves:

These students' - the Indigenous, the refugee, the immigrant, and the children of immigrants - senses of belonging are regulated by Whiteness in different ways in everyday settings and often through seemingly innocuous micro-practices including questions such as, "Where are you from?" and statements such as, "you are just like us" (Cruz \& Sonn, 2015, p. 139).

The descendants of migrants are always confronted with the need "to justify their presence". Frequently, they are interrogated about their origins and their loyalty towards the country where they were born. Societies that have experienced a strong wave of migration must act as diverse societies on the cultural, linguistic and religious levels, but also regarding the physical appearance of its inhabitants. As stated by Shin (2015), we need to rethink our models used in analysing the identity of ethnic minorities:

When we consider the complexity of constructs meant to reflect how individuals view themselves in terms of race and/or ethnicity, it seems almost nonsensical to rigidly promote theoretical models that are based on the assumption that all members of a particular racial group perceive and experience racial issues similarly (Shin, 2015, p. 13).

As far as the education system is concerned, analysis and research based on the nationality variable are sometimes irrelevant, to the extent that this variable throws little light on the languages spoken by individuals or their connection with their 
culture(s). The variable of country of birth or age at which they arrived in the host country may provide more appropriate information about the situation of migrant pupils in the school.

\section{Conclusion}

Driven by globalization, and the circulation of human-beings and ideas across the world (despite a few obstacles), international migrations have expanded considerably over recent decades. This has automatically resulted in the spread of cultural diversity in societies and in education systems, transforming a number of metropolises into multicultural cities (Abdul Qadeer, 2016).

Recently, international migrations have raised fear and concern. However, their global volume in relation to the world's total population remains modest. It is estimated that, in the future, a maximum of $5-10 \%$ of the world's population will live in a country different to that of its birth. This modest percentage will not prevent some parts of the world - the richest countries-from counting a high proportion of migrants.

While migrations have signified economic prosperity for individuals and countries (economic growth for the host countries and the flow of money to the countries of origin), modern migratory policies have tended towards the increased tightening of frontiers against migrants originating in the South. Beyond issues associated with international solidarity, the ageing of the population in industrialized countries will nevertheless stimulate them to encourage international migration.

The wave of migration affecting industrialized countries has brought with it not only political changes exemplified by the progressive rise in power of openly xenophobic political parties, but it obliges all the concerned countries to consider their collective identity(ties), as well as to review matters concerning integration and inclusion. The centrality of work as a positive and legitimate good has suffered as a result of globalization. In this same way, the term "migrant" or "refugee" has gradually replaced terms such as "guest worker" or "immigrant worker".

Beyond any economic or political argument, it is important to understand the extent to which migration has transformed the school. It has assumed an important role in the development of pupils' hybrid identities and in understanding the issues associated with interdependence between countries and intercultural relations. The school has become a major player in the way diversity is dealt with in our modern societies. Throughout this book, the reader will discover the challenges confronting it, but also the initiatives it has launched to promote cultural diversity. 
Open Access This chapter is licensed under the terms of the Creative Commons Attribution 4.0 International License (http://creativecommons.org/licenses/by/4.0/), which permits use, sharing, adaptation, distribution and reproduction in any medium or format, as long as you give appropriate credit to the original author(s) and the source, provide a link to the Creative Commons license and indicate if changes were made.

The images or other third party material in this chapter are included in the chapter's Creative Commons license, unless indicated otherwise in a credit line to the material. If material is not included in the chapter's Creative Commons license and your intended use is not permitted by statutory regulation or exceeds the permitted use, you will need to obtain permission directly from the copyright holder.

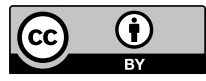

